University of New Hampshire

University of New Hampshire Scholars' Repository

$9-2007$

\title{
Validation and refinement of allometric equations for roots of northern hardwoods
}

\author{
Matthew A. Vadeboncoeur \\ Brown University, matt.vad@unh.edu \\ Steven P. Hamburg \\ Brown University \\ Ruth D. Yanai \\ SUNY College of Environmental Science and Forestry
}

Follow this and additional works at: https://scholars.unh.edu/ersc

Part of the Ecology and Evolutionary Biology Commons, and the Forest Sciences Commons

\section{Recommended Citation}

Vadeboncoeur MA, Hamburg SP, Yanai RD. 2007. Validation and refinement of allometric equations for roots of northern hardwoods. Canadian Journal of Forest Research 37:1777-1783

This Article is brought to you for free and open access by the Institute for the Study of Earth, Oceans, and Space (EOS) at University of New Hampshire Scholars' Repository. It has been accepted for inclusion in Earth Systems Research Center by an authorized administrator of University of New Hampshire Scholars' Repository. For more information, please contact Scholarly.Communication@unh.edu. 


\title{
Validation and Refinement of Allometric Equations for Roots of Northern Hardwoods
}

\author{
Matthew A. Vadeboncoeur ${ }^{1 *}$, Steven P. Hamburg ${ }^{1}$, and Ruth D. Yanai ${ }^{2}$ \\ 1. Center for Environmental Studies, Brown University \\ 2. SUNY College of Environmental Science and Forestry \\ *current address: \\ Earth Systems Research Center, University of New Hampshire \\ matt.vad@unh.edu
}

\begin{abstract}
The allometric equations developed by Whittaker et al. (1974) at the Hubbard Brook Experimental Forest have been used to estimate biomass and productivity in northern hardwood forest systems for over three decades. Few other species-specific allometric estimates of belowground biomass are available, because of the difficulty of collecting the data, and such equations are rarely validated. Using previously unpublished data from Whittaker's sampling effort, we extended the equations to predict the root crown and lateral root components for the three dominant species of the northern hardwood forest: American beech, yellow birch and sugar maple. We also refined the allometric models by eliminating the use of very small trees for which the original data were unreliable.

We validated these new models of the relationship of tree diameter to the mass of root crowns and lateral roots using root mass data collected from 12 northern hardwood stands of varying age in central New Hampshire. These models provide accurate estimates of lateral roots $(<10 \mathrm{~cm}$ diameter) in northern hardwood stands $>20$ years old (mean error 24-32\%). For the younger stands we studied, allometric equations substantially underestimated observed root biomass (mean error $>60 \%$ ), presumably due to remnant mature root systems from harvested trees supporting young root-sprouted trees.
\end{abstract}

This reformatted accepted manuscript is made available by the authors, in accordance with the author rights policy of NRC Research Press.

The formatted final version is available from the publisher at http://dx.doi.org/10.1139/X07-032

This document should be cited as:

Vadeboncoeur, M.A., S.P. Hamburg, and R.D. Yanai. 2007. Validation and refinement of allometric equations for roots of northern hardwoods. Canadian Journal of Forest Research 37(9): 1777-1783. 


\section{Introduction}

With increasing focus on global, regional, and local carbon cycles, the ability to accurately predict forest biomass has taken on a new urgency. Over the past half century a large number of allometric equations have been developed that allow prediction of standlevel biomass and regional $C$ stocks and investigation of the influence of specific allometric models on these estimates (Hamburg et al. 1997). Most of this work, however, has focused on aboveground biomass and not belowground biomass. Belowground biomass has most often been estimated with generalized root:shoot ratios, the variation in which is unfortunately not easily explained by latitude or soil type (Cairns et al. 1997), but may be explained in part by aboveground biomass, climate, and forest height (Mokany et al. 1998). The great degree of variation in these ratios (Mokany et al. 1998) makes it desirable to estimate stand-level belowground biomass using species- or forest-type-specific equations where available.

Utilizing data collected in 1965, Whittaker et al. (1974) reported allometric models to predict aboveand belowground tree biomass for sugar maple (Acer saccharum Marsh.), American beech (Fagus grandifolia Ehrh.), and yellow birch (Betula allegheniensis Britton) in addition to other species. These equations have been the sole source of allometrically derived belowground biomass estimates in the northern hardwood forest type (Jenkins et al. 2004). However, these equations did not distinguish between root crowns and the rest of the root system, and they had been validated only in the mature Hubbard Brook Experimental Forest (Fahey et al. 1988).

Separate equations that partition belowground biomass into two components, root crowns and lateral roots, would be useful in studies of root dynamics, as these pools have different chemical compositions and rates of decomposition (Fahey et al. 1988; Fahey and Arthur 1994). Likewise, coarse lateral roots, those with a diameter $>2 \mathrm{~mm}$, differ from fine roots in composition and turnover rates, but are much more difficult to sample (Park 2006). Subtracting fine root mass, which can be measured reliably with soil corers (Park et al. 2007), from allometrically estimated lateral root mass could provide estimates of coarse lateral roots, an important $\mathrm{C}$ pool.
The first objective of this study was to develop more precise equations for estimating belowground biomass in northern hardwoods, based on the data collected in 1965 by Whittaker et al. (1974). In addition to eliminating the smallest trees from the data set, which had contributed considerable uncertainty to the models, we also developed equations specific to root crown and lateral root mass, thus making the allometric models more compatible with field-based measurements of root biomass, which typically include only lateral roots. We compare the revised species-specific and generalized equations to those published by Whittaker et al. (1974) for total belowground biomass. The second objective of this study was to validate the accuracy of the lateral root equations using root mass data from 36 quantitative soil pits excavated to the $\mathrm{C}$ horizon from 12 northern hardwood stands of varying age in the White Mountain region (New Hampshire, USA). This exercise allowed us to evaluate whether the equations are accurate for forests of all ages and whether species-specific equations are likely to be necessary.

\section{Data and Methods - Revised Biomass Equations}

The allometric equations developed by Whittaker et al. (1974) were based on 14 trees of each of the tree species sampled in the Hubbard Brook Experimental Forest. Trees were collected from three elevational bands: $550-630 \mathrm{~m}, 630-710 \mathrm{~m}$, and $710-785 \mathrm{~m}$. The two lower elevation bands are occupied by northern hardwood forests on 1-3 m of glacial till. The highest elevation band is a transitional forest type between northern hardwood species and the balsam fir (Abies balsamea L.) and red spruce (Picea rubens Sarg.) zone, on much thinner soil (Bormann et al. 1970). Species-specific equations for the dry biomass of many tree components were developed using trees collected from the two lower elevational bands, and generalized equations (lumping the three species) were developed for each of the three elevational bands. Although component regressions for lateral roots and root crowns were not published, biomass by component by species was reported for each elevational band.

Root crowns were not explicitly defined by Whittaker et al. (1974), but are understood to be the 
uppermost parts of the root system that buttress the stem (Figure 1). We use the term "lateral roots" to refer to all belowground biomass exclusive of the root crown. Lateral roots and root crowns were defined operationally in the 1965 sampling. After a tree was felled and the stump cut to ground level, roots were "excavated with the encouragement of dynamite sticks set under and around the root crowns" (Whittaker et al. 1974). Lateral roots were cut from the crowns, presumably where the root begins to swell near its junction with the base of the tree, and combined with roots excavated from within the crater. A subset of roots were excavated outward from the crater, and a correction factor (described by Whittaker and Woodwell 1968) based on cut root diameter was used to account for the unsampled fraction of lateral roots. It is not known what diameter threshold or other criterion was used to separate lateral roots from crowns, nor what minimum cut root diameter was used in the correction procedure.

In our analysis, we assume that lateral roots as defined by Whittaker et al. (1974) correspond with roots $<10 \mathrm{~cm}$ in diameter, which is the diameter class for which we have data for validation (Yanai et al. 2006; Park et al. 2007). Quantitative pit estimates of root biomass in the $>2 \mathrm{~cm}$ size class have large relative errors (Park et al. 2007), as roots in excess of $\sim 5 \mathrm{~cm}$ diameter are encountered infrequently, in part because it is difficult to properly excavate a quantitative soil pit close to a large tree (Fahey et al. 1988; Yanai et al. 2006; Park et al. 2007).

The 1965 biomass dataset is largely intact and was previously used to revise the aboveground biomass equations (Siccama et al. 1994). Within each category (species by elevation range), for unknown reasons, a small number of trees (3 or fewer) do not have separate data on root crowns and lateral roots. This analysis is therefore based on fewer trees than the original analysis (Whittaker et al. 1974). Fortunately, the remaining data are still distributed across all diameter at breast height (dbh) size classes (Table 1).

Small trees $<2 \mathrm{~cm}$ dbh are problematic in the 1965 data set, having very high variance in root mass due to a few extreme outliers. Two trees, one sugar maple and one yellow birch, had root:shoot ratios > 4 , while all other trees had ratios between 0.1 and
0.6. Additionally, some trees $<2 \mathrm{~cm}$ dbh had more lateral root biomass estimated by the correction factor rather than by the sampled roots. In our analysis of the allometric data, we have omitted the four trees $<2 \mathrm{~cm} d b h$, leaving nine or more trees for each regression. Very few allometric equations include roots from trees $<2 \mathrm{~cm}$ dbh (Tritton and Hornbeck 1982; Jenkins et al. 2004), and such trees are of very limited importance to the estimation of stand biomass except in young stands (Schroeder et al. 1997), where these equations are probably not appropriate. The dbh of sampled trees in the reanalysis ranges from approximately $5 \mathrm{~cm}$ to $>50$ $\mathrm{cm} \mathrm{dbh}$ for all three species. We did not include red spruce in our reanalysis, as the data are missing. Striped maple (Acer pennsylvanicum L., which according to Siccama et al. 1994, was erroneously referred to as mountain maple (Acer spicatum Lam.) by Whittaker et al. 1974), was also excluded as there were few samples (total $n=10$ across all elevations), and it contributes little biomass in most northern hardwood stands, including those we studied.

We classified the revised equations as "significantly different" from the original equations when the 95\% confidence interval on the revised slope or intercept regression parameters did not include the parameter values published by Whittaker et al. (1974). Pairwise comparisons were also made among the speciesspecific and generalized equations for each biomass category; equations with overlapping 95\% confidence intervals of both the slope and intercept parameters were deemed insignificantly different.

\section{Methods - Validation}

To validate the lateral root equations we developed, we used root data collected from quantitative soil pits excavated in 2003 and 2004 in twelve stands (3 pits per stand) in and near the Bartlett Experimental Forest, about $40 \mathrm{~km}$ east of Hubbard Brook (Yanai et al. 2006; Park et al. 2007). The stands had all been cut at least once, and ranged in age from 14 years to 121 years and in elevation between 330 and $630 \mathrm{~m}$. The older (56-121 y) stands were dominated by the three northern hardwood species for which we have equations. The young (14-16 y) and youngtransitional (19-29 y) stands included these species as well as early successional species such as white birch (Betula papyrifera Marsh.), bigtooth aspen 
(Populus grandidentata Michx.), and pin cherry (Prunus pennsylvanica L.f.).

Roots were excavated to the $C$ horizon from three $0.5 \mathrm{~m}^{2}$ soil pits in each of the twelve stands. Pit locations were rejected if they had $>50 \%$ surface rock cover, if they were too rocky in the subsurface to allow 3 pieces of rebar to be driven deep enough to secure the digging frame, or if there was a tree with $\mathrm{dbh} \geqq 10 \mathrm{~cm}$ within $0.5 \mathrm{~m}$ of the pit center. Together, these criteria resulted in a pit location rejection rate of $31 \%$, with the majority of rejections based on the rock criteria (these sites had up to $20 \%$ surface rock by area). Based on stem density of trees $\geqq 10 \mathrm{~cm}$ dbh in our sites, we would expect the tree proximity criterion to result in a rejection rate of up to $10 \%$ in the mid-aged sites, and approximately $1 \%$ in both young and older sites.

Quantitative soil pits were excavated using an updated method based on Hamburg (1984) and Huntington et al. (1988). While belowground biomasss sampling was not the primary purpose for excavating this set of soil pits, roots were collected with far more care than in similar previous studies (e.g. Fahey et al. 1988). Roots from each soil horizon were collected on a $12 \mathrm{~mm}$ sieve, washed, sorted by diameter class, and weighed. Soil that passed the 12 $\mathrm{mm}$ sieve was subsampled, picked for roots $>5 \mathrm{~mm}$ in length, and thoroughly elutriated several times to float fine roots onto $1 \mathrm{~mm}$ screens. This procedure was repeated until visual inspection of the soil revealed no remaining fine roots. Total live root masses were reported for various size classes of roots (Yanai et al. 2006; Park et al. 2007); we used data from roots $<10 \mathrm{~cm}$ diameter (Figure 1 ) for comparison with lateral root mass estimated with allometric equations.

To estimate lateral root mass using allometric equations, we recorded the species and $\mathrm{dbh}$ of all trees $\geqq 10 \mathrm{~cm}$ dbh within $6 \mathrm{~m}$ of the pit center, and of all trees $\geqq 2 \mathrm{~cm}$ dbh within $3 \mathrm{~m}$. We refer to these data as "pit-level" inputs to the allometric equations. We also characterized the species and dbh of trees at the site level. Within inventory plots totaling $2700 \mathrm{~m}^{2}$ per site, we tallied all trees $\geqq 10 \mathrm{~cm}$; trees $\geqq$ $2 \mathrm{~cm}$ but $<10 \mathrm{~cm}$ were tallied in nested subplots totaling $375 \mathrm{~m}^{2}$ per stand. We used these data to test how well the pit-level data and the stand-level data predicted the observed root masses.
Because we have lateral root equations for only three of the 16 tree species in our plots, we assigned each of the other species to one of the available equations based on growth form. The American beech equation was used for white ash (Fraxinus americana L.) and northern red oak (Quercus rubra L.). The sugar maple equation was used for red maple (Acer rubrum L.), striped maple, American basswood (Tilia americana L.), and eastern hophornbeam (Ostrya virginiana (Mill.) K. Koch). The yellow birch equation was used for white birch, quaking aspen (Populus tremuloides Michx.), bigtooth aspen, pin cherry, and black cherry (Prunus serotina Ehrh.). The percentage of trees for which such proxy substitutions were necessary ranged from $3 \%$ in a mature stand dominated by the three modeled species to $62 \%$ in a young stand dominated by pin cherry and white birch. White birch was the most important species in our plots without its own equation, followed by pin cherry and red maple. No other species without a specific equation accounted for more than $8 \%$ of basal area at any site.

To estimate the root mass of conifer species, we used the red spruce equation from Whittaker et al. (1974) for red spruce, balsam fir, and eastern hemlock (Tsuga canadensis L.) with a 0.627 scalar to convert total belowground biomass to lateral root mass. This scalar is the mean ratio of red spruce lateral root mass to red spruce total belowground biomass at the stand level reported by Whittaker et al. (1974). The uncertainty introduced by this assumption is small, since conifers accounted for $\leq 5 \%$ of total basal area in all stands.

Assembling groups of comparable species for biomass equations is especially problematic for tree components, such as roots (Jenkins et al. 2003). To test the importance of species assignments on the accuracy of the predictions, we repeated the validation using only the generalized hardwood equation (Table $1 \mathrm{~b}$ ) for the same elevation range (550-710m) on all trees, including conifers.

The dbh range of the data used to generate the equations was largely adequate for the stands in which we sampled roots in soil pits. In the inventories around the pits, only two sugar maple trees ( $\mathrm{dbh}$ of 48 and $82 \mathrm{~cm}$ ) exceeded the range of the species-specific equation. The two younger sites had a significant proportion of basal area (22-55\%) in trees below the minimum used in any of the 
equations used $(3.2 \mathrm{~cm})$, as well as a large number of trees $\leq 2 \mathrm{~cm}$ dbh that we did not measure. For this reason, we validated the root mass predicted by the equations separately by age class, with the expectation that the equations might not predict root mass accurately in the young sites. To compare our revised equations with those published by Whittaker et al. (1974), we calculated total belowground biomass using the published equations and applying species-specific scalars to convert total belowground biomass to lateral root mass; 0.637 for sugar maple, 0.706 for American beech, and 0.615 for yellow birch. These ratios are derived from stand-level component biomass data reported by Whittaker et al. (1974), and have until now been the only way to estimate lateral roots in northern hardwoods (e.g. Fahey et al. 1988).

For each combination of allometric equation type and input data set, we calculated the following two error metrics,

Systematic Bias $=\frac{\sum_{i=1}^{n} \frac{p_{i}-m_{i}}{m_{i}}}{n}$

and

Mean Absolute Error $=\frac{\sum_{i=1}^{n}\left|\frac{p_{i}-m_{i}}{m_{i}}\right|}{n}$

where $n$ is the number of sites in the input data set, $p_{i}$ is the allometrically predicted root biomass at site $i$, and $m_{i}$ is the measured root biomass at site $i$ based on quantitative soil pits.

\section{Results - Revised Biomass Equations}

In general, the revised data set yields equations for total belowground biomass with slightly lower intercepts and higher slopes than the comparable equations reported by Whittaker et al. in 1974 (Table 1a). A consequence of this difference is that the revised equations predict lower root mass at low $\mathrm{dbh}$, and higher root mass at high dbh (Figure 2). The differences are largely a consequence of the removal of low-dbh trees with high root mass values, although the regressions are also affected to a small degree by the omission of now-missing data. In the revised equations, there is a trend towards higher intercepts and lower slopes as elevation increases, both for total belowground biomass (Table 1a) and for lateral root mass (Table 1b), although the trend is less clear for root crown mass (Table 1c). However, the difference in slope and intercept parameters across this elevational gradient is not significant at the $\alpha=0.05$ level.

The equations for yellow birch have the greatest slope and lowest intercept among the three species studied (Table 1), as is true in the original equations published by Whittaker et al. (1974). However, in no case is the slope or intercept parameter for any species (in the Low + Mid elevation range) significantly different than that for any other species.

\section{Results - Validation}

The allometric equation predictions agree well with observed root mass from the soil pits in the youngtransitional and mature stands. The lateral root mass predicted by applying the revised speciesspecific allometric equations to the pit-level data shows a strong relationship with observed root mass $\left(r^{2}=0.55, p=0.014\right)$, in a comparison of stand means ( $n=3$ pits per stand) from 10 sites (Figure 3 ).

This comparison excludes the young stands (14 and 16 years) because these sites have both a high proportion of unmeasured basal area and a high density of stump- and root-sprouted trees, which deviate from canonical root-shoot ratios due to the different ages of the above- and belowground portions of the tree (Whittaker and Woodwell 1968). Allometric equations developed in mature forests are an inappropriate tool for predicting root biomass in such stands. While lateral root mass was systematically underpredicted by approximately $70 \%$ in young stands, older stands (56-121 years) had between $20 \%$ and $30 \%$ bias (calculated as mean relative error by site) towards overprediction, depending on the model and input data used (Figure 3 , Table 2a). Bias was small and the direction varied by model in the young-transitional stands. One stand in this age class was similar to the young stands in the degree to which the equations underpredicted the observed root mass (age 26, Figure 3).

As might be expected, the tree inventory data collected immediately around the pits excavated for root biomass (pit-level data) were better at 
predicting observed root biomass than stand-level data collected from the $2700 \mathrm{~m}^{2}$ plot area. In 13 out of 15 possible comparisons (the three groups of allometric equations applied to three age classes of stands, all stands together, and all stands except young stands), mean absolute error was less using the pit-level data than using stand-level data (Table 2b). However, the magnitude of this difference was surprisingly small, never accounting for more than $8 \%$ error, or a quarter of the total stand-level error. Variation in tree density at the scale of the tens of meters separating our pits is evidently less important than fine-scale $(<1 \mathrm{~m})$ spatial heterogeneity in root density and the intrinsic error of predicting root mass with allometric equations.

Mean absolute error for each age group was similar across the types of equations (Table 2 ). The generalized lateral root equations were not significantly worse predictors than the speciesspecific equations, as the differences in equations by species were not great (Table 1). Also, the young transitional sites, with their high numbers of species without specific equations of their own, were predicted with the same accuracy as the older sites, for which most species were represented in our data set (Table 2).

Mean absolute error of root biomass predictions in these sites was higher (24\% to $32 \%$, depending on the equations used and the input data) than the $8 \%$ error of Whittaker's aboveground biomass equations applied to three plots destructively sampled for aboveground biomass in a stand at Hubbard Brook Experimental Forest less than $1 \mathrm{~km}$ from the stand where the equations were developed (Arthur et al. 2001). The higher error of root biomass predictions is not surprising, given that the area excavated for roots in each site was only $1.5 \mathrm{~m}^{2}$, compared to 2500

$\mathrm{m}^{2}$ from which Arthur et al. (2001) validated aboveground biomass. More extensive validation data for lateral roots and crowns would be difficult to obtain, but could answer important questions about the sources of variation and uncertainty in belowground biomass estimates.

\section{Conclusions}

The revised allometric equations reported here are based on a more selective data set, and will provide more slightly more precise estimates of belowground biomass than those previously published. More importantly, they provide the ability to separate belowground biomass into lateral roots and crowns, which allows these pools to be separately modeled and validated. Unfortunately, we don't know the exact definition of crowns and lateral roots used in Whittaker's study; we used a cutoff of $10 \mathrm{~cm}$ in our validation. Future studies should take care to define their root classes, morphologically or with a diameter cutoff.

The allometric approach is shown to be valid for mid- to late-successional northern hardwoods ( $>20$ years since cutting), based on a comparison of measured lateral root biomass in 10 stands. In contrast, in young northern hardwood stands, lateral root biomass cannot be predicted from species and diameter of tree stems, due in part to stump sprouting and stem thinning, which result in smaller and fewer stems relative to belowground biomass. The generalized northern hardwood equations (Table 1) have similar accuracy to species-specific equations (Table 2), when applied in mixed northern hardwood stands of varying age and species composition.

\section{Acknowledgements}

We thank Byung Bae Park for the root data from the soil pits and his help in interpreting the results of the comparison. Tom Siccama was helpful in interpreting the data from the 1965 sampling. Mary Arthur had many helpful comments on the manuscript, and along with Joel Blum and Elizabeth Hane, was integral to the development and implementation of the soil pit project. Roots were excavated, sorted, washed, dried, and weighed by dozens of student workers in 2003 and 2004. This work was funded by the National Science Foundation (DEB 0235650 and DEB 9810221) and is a contribution to the Hubbard Brook Ecosystem Study.

\section{Literature Cited}

Arthur, M. A., S. P. Hamburg and T. G. Siccama. 2001. The accuracy of allometric estimates of aboveground living biomass and nutrient contents of a northern hardwood forest. Canadian Journal of Forest Research 31:11-17.

Bormann, F. H., T. G. Siccama, G. E. Likens, and R. H. Whittaker. 1970. The Hubbard Brook Ecosystem 
Study: Composition and dynamics in the tree stratum. Ecological Monographs 40:373-388.

Cairns, M. A., Brown, S., Helmer, E. H., and Baumgardner, G. A. 1997. Root biomass allocation in the world's upland forests. Oecologia. 111:1-11.

Fahey, T. J., J. W. Hughes, M. Pu, and M. A. Arthur. 1988. Root decomposition and nutrient flux following whole-tree harvest of northern hardwood forest. Forest Science 34:744-768.

Fahey, T. J. and M. A. Arthur. 1994. Furthers studies of root decomposition following harvest of a northern hardwood forest. Forest Science 40:618629.

Hamburg, S. P. 1984. Effects of forest growth on soil nitrogen and organic matter pools following release from subsistence agriculture. pp. 145-158. In: E. L. Stone (ed.). Forest Soils and Treatment Impacts. Proc. Sixth North American Forest Soils Conf. University of Tennessee, Knoxville.

Hamburg, S. P., D. G. Zamolodchikov, G.N. Korovin, V.V. Nefedjev, A.I. Utkin, J.I. Gulbe and T.A. Gulbe. 1997. Estimating the carbon content of Russian forests; a comparison of phytomass/volume and allometric projections. Mitigation and Adaptation Strategies for Global Change. 2:247-265.

Huntington, T. G., D. F. Ryan and S. P. Hamburg. 1988. Estimating soil nitrogen and carbon pools in a northern hardwood forest ecosystem. Soil Science Society of America Journal 52:1162-1167.

Jenkins, J. C., D. C. Chojnacky, L. S. Heath, and R. A. Birdsey. 2003. National-scale biomass estimators for United States tree species. Forest Science 49:12-35.

Jenkins, J. C., D. C. Chojnacky, L. S. Heath, and R. A. Birdsey. 2004. Comprehensive database of diameter-based biomass regressions for North American tree species. USDA Forest Service. General Technical Report NE-319.
Mokany, K., R.J. Raison, and A.S. Prokushkin. 1998. Critical analysis of root:shoot ratios in terrestrial biomes. Global Change Biology 12:84-96.

Park, B.B. 2006. Fine root dynamics and tissue chemistry across a calcium gradient in temperate hardwood and softwood forest ecosystems. Ph. D. Thesis. State University of New York, College of Environmental Science and Forestry, Syracuse, NY, 246 pp.

Park, B. B., R. D. Yanai, M. A. Vadeboncoeur, and S. P. Hamburg. 2007. Estimating root biomass in rocky soils using pits, cores, and allometric equations. Soil Science Society of America Journal. In press.

Schroeder, P., S. Brown, J. Mo, R. Birdsey, and C. Cieszewski. 1997. Biomass estimation for temperate broadleaf forests of the US using inventory data. Forest Science 43:424-434.

Siccama, T. G., S. P. Hamburg, M. A. Arthur, R. D. Yanai, and G. E. Likens. 1994. Corrections to allometric equations and plant tissue chemistry for Hubbard Brook Experimental Forest. Ecology 75:246-248.

Tritton, L. M., and J. W. Hornbeck. 1982. Biomass equations for major tree species of the northeast. USDA Forest Service. General Technical Report NE-GTR-69.

Whittaker, R. H., F. H. Bormann, G. E. Likens, and T. G. Siccama. 1974. The Hubbard Brook Ecosystem Study: Forest biomass and production. Ecological Monographs 44:233-252.

Whittaker, R. H., and G. M. Woodwell. 1968. Dimension and production relations of trees and shrubs in the Brookhaven Forest, New York. Journal of Ecology 56:1-25.

Yanai, R. D., Park, B. B., and S. P. Hamburg. 2006. The vertical and horizontal distribution of roots in northern hardwood stands of varying age. Canadian Journal of Forest Research 36:450-459. 
Table 1. Parameters with standard errors for equations relating (a) total belowground biomass, (b) lateral root mass, and (c) root crown mass to tree diameter for northern hardwood species at the Hubbard Brook Experimental Forest. The lateral root and the root crown masses were measured but not reported by Whittaker et al. (1974). All single-species equations are regressions utilizing data from the combined Low and Mid (550-710 m) elevation band only.

a) $\log _{10}$ (Total belowground dry biomass in grams) $=A+B \log _{10}(\mathrm{dbh}$ in $\mathrm{cm})$

\begin{tabular}{lrrrrrrr}
\hline Group & $\begin{array}{r}\text { dbh range } \\
(\mathbf{c m})\end{array}$ & $\boldsymbol{n}$ & A (std err) & \multicolumn{2}{c}{ B (std err) } & $\mathbf{r}^{2}$ \\
Acer saccharum & $3.2-47.0$ & 10 & $* 1.6546$ & $(0.1294)$ & 2.2636 & $(0.0997)$ & 0.985 \\
Betula allegheniensis & $3.4-51.0$ & 12 & $* 1.3549$ & $(0.1450)$ & 2.4891 & $(0.1091)$ & 0.981 \\
Fagus americana & $6.2-49.5$ & 9 & 1.6070 & $(0.1799)$ & 2.3278 & $(0.1302)$ & 0.979 \\
All northern hardwood, Low $(550-630 \mathrm{~m})$ & $6.1-51.0$ & 15 & $* 1.4110$ & $(0.0929)$ & $* 2.4418$ & $(0.0672)$ & 0.990 \\
All northern hardwood, Mid $(630-710 \mathrm{~m})$ & $3.2-50.0$ & 16 & 1.5766 & $(0.1381)$ & 2.3407 & $(0.0173)$ & 0.971 \\
All northern hardwood, Low and Mid & $3.2-51.0$ & 31 & 1.5120 & $(0.0845)$ & 2.3796 & $(0.0633)$ & 0.980 \\
All northern hardwood, High (710-785 m) & $2.3-59.0$ & 18 & 1.6957 & $(0.0978)$ & 2.2027 & $(0.0738)$ & 0.982 \\
\hline
\end{tabular}

b) $\log _{10}$ (Lateral root dry biomass in grams) $=A+B \log _{10}(\mathrm{dbh}$ in $\mathrm{cm})$

\begin{tabular}{llllll}
\hline Group & A (std err) & B (std err) & $\mathbf{r}^{2}$ \\
Acer saccharum & 1.3489 & $(0.1400)$ & 2.3348 & $(0.1079)$ & 0.983 \\
Betula allegheniensis & 1.1475 & $(0.1699)$ & 2.4937 & $(0.1278)$ & 0.974 \\
Fagus americana & 1.3278 & $(0.2894)$ & 2.4058 & $(0.2096)$ & 0.950 \\
All northern hardwood, Low & 1.2290 & $(0.1293)$ & 2.4481 & $(0.0935)$ & 0.981 \\
All northern hardwood, Mid & 1.2711 & $(0.1687)$ & 2.4081 & $(0.1311)$ & 0.960 \\
All northern hardwood, Low and Mid & 1.2501 & $(0.1046)$ & 2.4288 & $(0.0784)$ & 0.971 \\
All northern hardwood, High & 1.5781 & $(0.1481)$ & 2.0739 & $(0.1117)$ & 0.956 \\
\hline
\end{tabular}

c) $\log _{10}$ (Root crown dry biomass in grams $)=A+B \log _{10}(\mathrm{dbh}$ in $\mathrm{cm})$

\begin{tabular}{lllll}
\hline Group & A (std err) & B (std err) & $\mathbf{r}^{2}$ \\
Acer saccharum & $1.3512(0.1875)$ & 2.1666 & $(0.1445)$ & 0.966 \\
Betula allegheniensis & $0.8747(0.1733)$ & 2.5142 & $(0.1304)$ & 0.974 \\
Fagus americana & $1.2379(0.1114)$ & $2.2213(0.0807)$ & 0.991 \\
All northern hardwood, Low & $0.9217(0.0923)$ & 2.4590 & $(0.0668)$ & 0.990 \\
All northern hardwood, Mid & $1.2448(0.1614)$ & 2.2665 & $(0.1254)$ & 0.959 \\
All northern hardwood, Low and Mid & $1.1278(0.1027)$ & 2.3214 & $(0.0770)$ & 0.969 \\
All northern hardwood, High & $1.1574(0.0905)$ & 2.3533 & $(0.0683)$ & 0.987 \\
\hline$*$ indicates parameters with 95\% confidence intervals that do not include the published value from Whittaker et al. (1974).
\end{tabular}


Table 2. Systematic bias (a) and mean absolute error (b) for three allometric models in predicting site mean lateral root mass for 12 northern hardwood forest stands of varying age. "Specific" refers to the revised species-specific lateral root equations from Table $1 \mathrm{~b}$. "General" refers to the lumped-species equation for lateral roots from the 550-710m elevation band (Table 1b). "Published" refers to the total belowground biomass equations from Whittaker et al. (1974), multiplied by a scalar to remove root crown mass, following Fahey et al. (1988). Systematic bias is calculated as the mean relative error across all sites in each group of sites (Equation 1). Mean absolute error is the mean absolute value of relative error across sites (Equation 2).

Input: pit-level tree data

\begin{tabular}{|c|c|c|c|c|c|c|}
\hline Allometric Model & Specific & General & Published & Specific & General & Published \\
\hline \multicolumn{7}{|l|}{ a) Systematic Bias } \\
\hline Young (14-16 y), $n=2$ & $-74 \%$ & $-74 \%$ & $-62 \%$ & $-75 \%$ & $-75 \%$ & $-64 \%$ \\
\hline Young transitional (19-29 y), $n=5$ & $-7 \%$ & $-3 \%$ & $13 \%$ & $-11 \%$ & $7 \%$ & $6 \%$ \\
\hline Older (56-121 y), $n=5$ & $22 \%$ & $27 \%$ & $20 \%$ & $27 \%$ & $29 \%$ & $26 \%$ \\
\hline All sites excluding young, $n=10$ & $7 \%$ & $12 \%$ & $17 \%$ & $8 \%$ & $11 \%$ & $16 \%$ \\
\hline All sites, $n=12$ & $-6 \%$ & $-2 \%$ & $3 \%$ & $-6 \%$ & $-3 \%$ & $3 \%$ \\
\hline
\end{tabular}

\section{b) Mean Absolute Error}

Young (14-16 y), $n=2$

Young transitional (19-29 y), $n=5$

Older (56-121 y), $n=5$

All sites excluding young, $n=10$

All sites, $n=12$

$\begin{array}{llllll}74 \% & 74 \% & 62 \% & 75 \% & 75 \% & 64 \% \\ 24 \% & 26 \% & 34 \% & 29 \% & 30 \% & 30 \% \\ 24 \% & 28 \% & 22 \% & 26 \% & 27 \% & 27 \% \\ 24 \% & 27 \% & 28 \% & 32 \% & 31 \% & 32 \% \\ 32 \% & 35 \% & 34 \% & 36 \% & 37 \% & 35 \%\end{array}$


Figure 1. Total belowground biomass is divided into two components: root crowns (the uppermost part of the root system attached to the stem) and lateral roots. Our validation data, which include lateral roots only, defined this category as comprising all roots up to $10 \mathrm{~cm}$ in diameter. It is not known whether what threshold was used by Whittaker et al. (1974) or whether they used a strict diameter threshold at all.

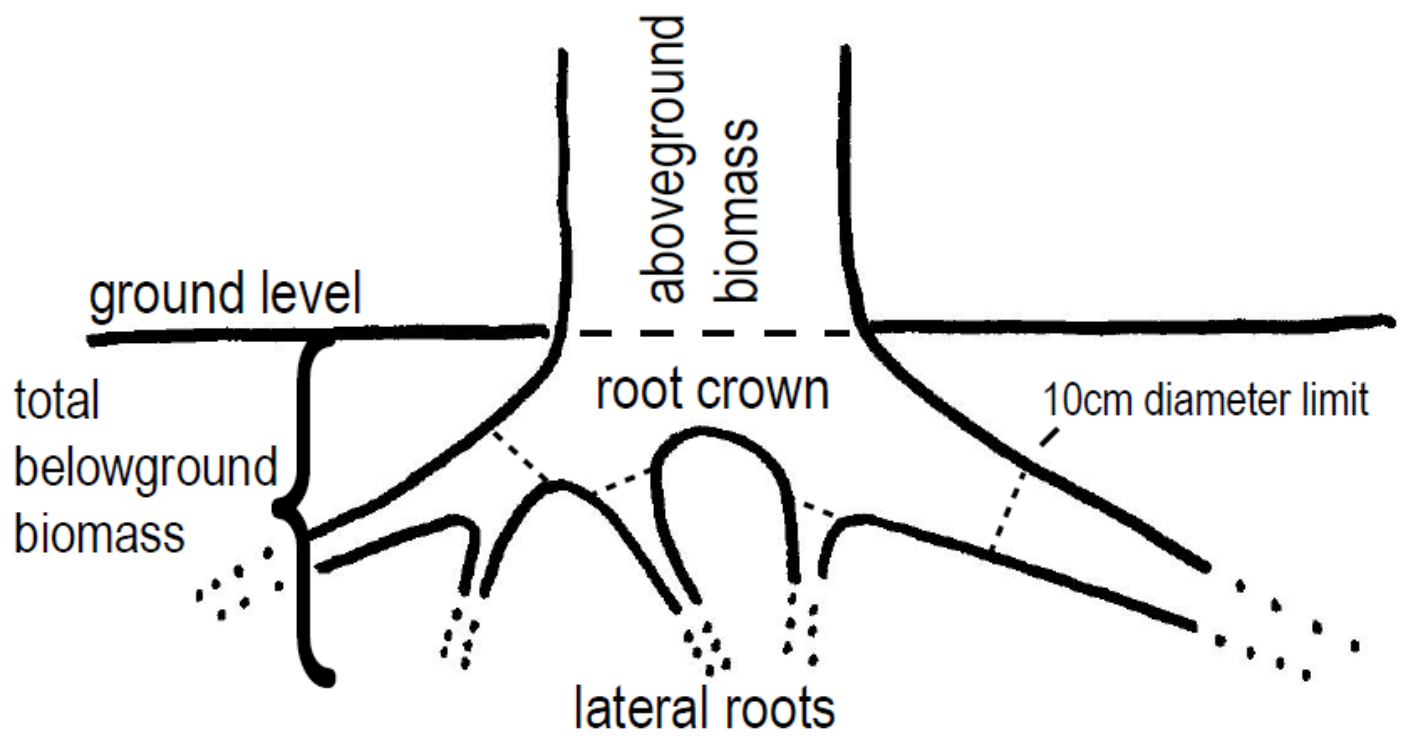


Figure 2. Ratio of total belowground biomass values predicted using revised equations (Table 1a) to those predicted by the equations published by Whittaker et al. (1974). Equations developed for each of the three individual species are shown as squares; equations developed for each of Whittaker's three general elevational groupings are shown as circles.

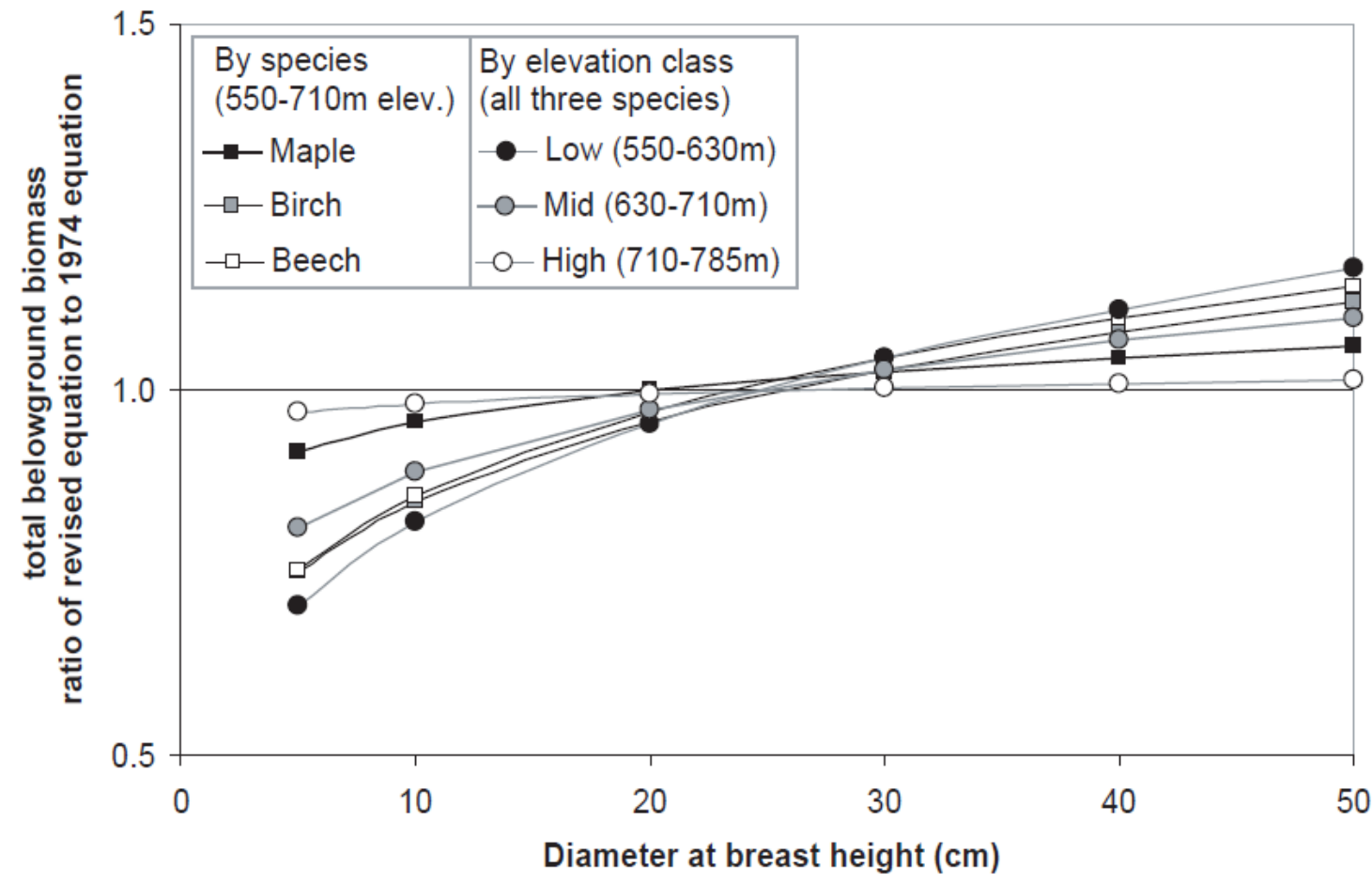


Figure 3. Observed lateral root mass (<10 cm diameter) at 12 northern hardwood stands of varying age (14 to 121 years old) plotted versus predicted lateral root mass (revised allometric equations applied to trees within 6 meters of each pit). The dashed line is a 1:1 relationship, and the solid line is the best fit regression $(p=0.01$ ) through all data excluding the two youngest sites. Site age in years is listed by each data point. Error bars are \pm 1 S.E.

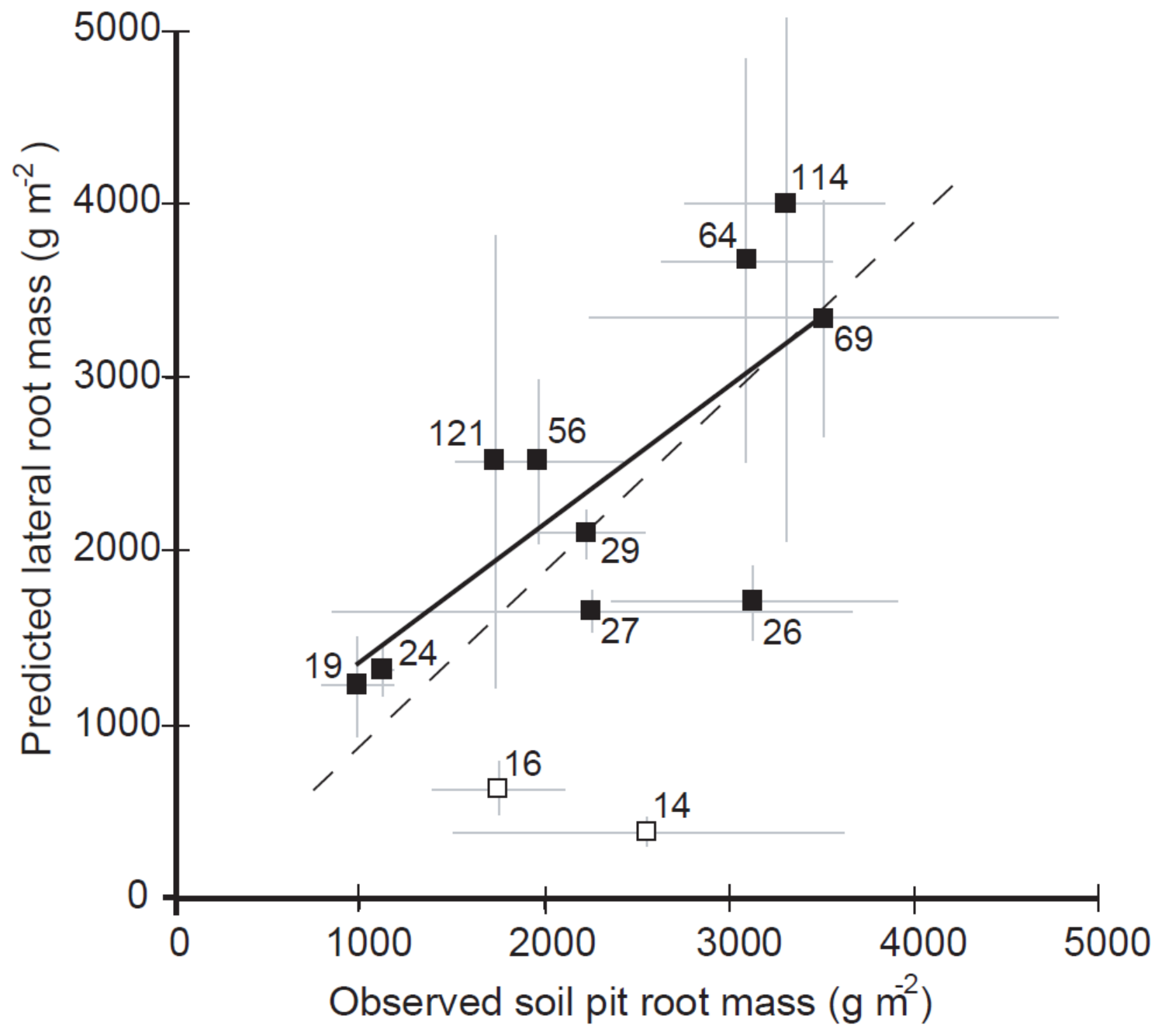

